\title{
Phylogenetic Relationship of Oats (Avena sativa L): A Guide to Conservation and Utilisation of Genetic Resources
}

\author{
Mushtaq Ahmad $^{1 *}$, I. A. Jehangir' ${ }^{1}$, R. Rizvan ${ }^{2}$, Showkat Ahmad Dar ${ }^{3}$, Shahida Iqbal', \\ S.H.Wani ${ }^{1}$, U. Mehraj ${ }^{1}$ and Rohie Hassan ${ }^{4}$ \\ ${ }^{1}$ MRCFC- KHUDWANI, ${ }^{2}$ Faculty of horticulture, ${ }^{3}$ Krishi Vigyan Kainder, Zanaskar, Ladakh, \\ Sher-e-Kashmir University of Agricultural Sciences \& Technology of Kashmir, \\ Shalimar, Srinagar, India \\ ${ }^{4}$ OPGS University Churu Rajasthan, India \\ *Corresponding author
}

\section{A B S T R A C T}

\section{Keywords}

Oats, Plant genetic resources,

Preservation, Exotic germplasm, Quality, Forage yield, Human consumption, Grain yield

Article Info

Accepted: 10 October 2020 Available Online: 10 November 2020

\begin{abstract}
The genus Avena is very large and highly diverse and contains both wild and cultivated species of polyploidy series with a basic chromosome number of $n=7$. Preservation of plant genetic resources is an essential tool for securing them for diverse utilisation in the future. They include commercial plant varieties (both currently available and those developed in the past) as well as traditional local plant varieties, landraces, wild material and breeding lines. The genetic base from which many of our present day varieties have been derived is quite narrow and frequently, pedigrees trace back to varieties. It has recently been demonstrated that allelic diversity at particular loci, rather than average genetic diversity, is sensitive to oat breeding practices. Base broadening of the present cultivated gene pool by introducing novel germplasm is becoming increasingly important and can be achieved in a number of different ways. Incorporation of exotic germplasm is the best means to enhance the genetic base of oat crop substantially with desirable grain quality and fodder yield. Various developments, including the introduction of intellectual property rights (IPR), have changed the ways in which plant genetic resources (PGR)are utilized by agriculture on a global basis. Now the whole scenario of this crop is changed because of highly nutritious for human consumption. To work hard in this crop, exploitation of genetic resources, wild relatives and innovative techniques for improvement of this crop for fodder as well as for human consumption.
\end{abstract}

\section{Introduction}

Oats (Avena sativa L.) belongs to family poaceae and ranks sixth in the world cereal production statistics following wheat, maize, rice, barley and sorghum. Oat is an important winter fodder, mostly fed as green but surplus is converted into silage or hay use during fodder deficit periods (Ahmad et al., 2015a). Oat as a forage crop has the advantage of being winter hardy and serves as catch crop (Morey, 1961). It is preferred feed of all animals and its straw is soft and grain is also valuable feed for horses, dairy cows, poultry 
and young breeding animals (Ahmad etal., 2014, 2015, 2010). The demand of meat, beef, milk, butter and their by-products is increasing due to rapidly growing human population in India (Ahmad and Zafar, 2014a). Oat protein is nearly equivalent in quality to soy protein, which has been shown by the World Health Organization to be equal to meat, milk, and egg protein (Ahmad et al., 2013). In Jammu and Kashmir state livestock population is 7.8 million so the fodder production(Ahmad et al., 2014, 2015) is not sufficient enough to meet the requirements of a burgeoning livestock population (Ahmad and Zafar. 2014b, 2014c; Anonymous, 2009). The farmers face fodder deficiency in winter when they have only dry stalks of summer cereal fodders or dry summer grasses. In order to increase in productivity per unit area there is need to develop varieties having higher forage yield potential and quality. The present production is not proportionate with the demand. So, oats deserves a deep deliberation for improvement. It should be highly pragmatic by the fact that, sixty corers animals will need 1097 and 1170 million tonnes of green fodder, respectively. In Jammu and Kashmir there is acute shortage of fodder for livestock husbandry particularly during winter. To improve the productivity of animals availability of adequate quantity of nutritive fodder is a prerequisite. An experiment was conducted during the winter (rabi) seasons (Jehangeer et al., 2013). Deficiency of green fodder will be about 64.9 per cent and for dry fodders it may go to up to 24.9 per cent in 2025 A.D (Ahmad et al., 2015 b). Forages of varying quality support different levels of production. Forage is important in the sense of providing fibre to ruminants. Inadequate levels of dietary fibre are associated with low milk fat, rumen acidosis and dietary inefficiency. Forages provide rumen buffering and improve the fermentation efficiency of starchy grains. Forage also provides effective fibre in dairy rations where $75 \%$ of ration neutral detergent fibre should come from coarse forages (Mehraj et al., 2016). Therefore, there is an urgent need of exploiting new research technologies to boost forage yield in terms of higher yield of green fodder and dry matter per unit are and also develop variety for human consumption. However, oat yield cannot compete with wheat and barley grain yields, in the other production areas. It needs improved grain yield for most of the production areas. Grain yield is the result of a number of complex morphological and physiological processes affecting each other and occurring in different growing stages (Mehraj et al., 2016). In general, oat breeders select varieties based on grain yield and desirable traits, observed from heading to maturity. Beside grain yield, spikelet's perpanicle, seed length breadth ratio and 1000 seed weight. Heterosis is an effect has been used in breeding of open pollinated plants such as maize or rye. At present hybrid breeding also being focused on self-pollinated plants (Ahmad et al., 2015a). Oat is considered to be nutritious source of protein, carbohydrate, fibre, vitamins, and minerals as well as of compounds with beneficial effects on health. As food oats are mostly preferred in breakfast items, oats are viewed by consumers as one of the whole some, healthiest; natural food with the result there is rising global food demand for oats and increasing production, milling and trade.

\section{Role of plant genetic resources and phylogenetic relationship}

Plant genetic resources for food and agriculture mean any genetic material of plant origin of actual or potential value for food and agriculture. They include commercial plant varieties (both currently available and those developed in the past) as well as traditional local plant varieties, landraces, wild material and breeding lines. Various developments, 
including the introduction of intellectual property rights (IPR), have changed the ways in which plant genetic resources (PGR) are utilized by agriculture on a global basis. While there have been a number of methods proposed to improve the efficiency of utilization of PGR during this time, any advances have been limited in their success. For example, the core collection method, while enjoying some popularity, has not completely delivered the advantages sought. It is proposed that significant advances can be achieved by focusing on several fundamental parameters associated with identifying PGR whilst employing some modern technologies. Basic passport information that uniquely identifies accessions is one such fundamental parameter. Database and GIS technology can be employed to recognize and more fully exploit the relationship between genotype, environment and evolution to more efficiently identify and utilize desirable genetic variation (Annamaa and Kukk, 2012). Preservation of plant genetic resources is an essential tool for securing them for diverse utilisation in the future. According to the international commitment arising from the ratification of the Convention on Biological Diversity (The Convention on ..., 1992), each country is responsible for conservation and sustainable use of plant genetic diversity as a local cultural and historical heritage to enhance the expediency of crop cultivation and ensure sustainable development of society. The systematic position of the species in genus Avena L. still remains disputable among researchers. Comparative analysis of the whole specific diversity of oats was incited by the profound interest to the use of these forms in taxonomy and breeding practice, enforces by the late development of plant immunological, biochemical and other researches. Further search for taxonomy and utilization of new oat breeding sources is one of the objectives pursued by Vavilov Institute of Plant Industry (VIR) in studying its global germplasm collections (Loskutov, 2000; 2001; 2002; 2003; Loskutov et al., 2001). The research presents the field results of studying (1988-2001), about 3000 accessions of 26 oat species with different ploidy level. Complex study of specific diversity and analysis of geographic distribution of the habitats of oat forms and species confirmed that the centre of origin of Arena L. lies in the western part of the Mediterranean region, while the secondary centre of formation of Avena species and origin of cultivated oat (A.sativa) is situated within the Asia Minor centre of crop origin. The analysis of intraspecific diversity helped to identify centres of morphogenesis for all cultivated oat species. The centre for the diploid sp. A.strigosa is Spain and Portugal, for the naked forms A.nuda L. UK, for the tetraploid species A.abyssinica it is Ethiopia, for the hexaploid species A.byzantina Algeria and Morocco, for the hulled forms of A.sativa Iran, Georgia and Russia (Tatarstan), and for its hull-less forms Mongolia and China. A revised taxonomic system for the species in the genus Avena based upon the degree of relationship with hexaploid species has been developed. We have divided this genus into two subgenera, sub geneA venastrum and a typical subgenAvena which is subdivided into Aristulatae Malz. u Denticulatae Malz. Such division according to the characters of the lemma tip - biaristulate or Aristulatae and bidentate or Denticulatae. The study was targeted at morphological characterization, agronomic traits and resistance to the most widespread diseases: crown and stem rusts, powdery mildew, Helminthic sporium leaf blotch, Septoria blight, Mirothecium necrotic mottle and BYDV. Representative collection of all species has been analyzed for groat protein content amino acid and groat oil content-fatty acid content. The study representative set of accessions of genus Avena L. Species with different ploidy levels helped to determine intraspecific diversity in 
all characters. A majority of identified sources may be directly involved in the breeding for disease resistance, agronomic traits and grain quality (Murariu et al., 2013; Ahmad et al., 2015b).

\section{Investigation of phylogenetic relationships}

N.I.Vavilov Institute of Plant Industry is harboured one of the largest collection of 4 cultivated and 22 wild oat species. There are more than 11700 cultivated and 2 000wild oat accessions there. It presents global genetic diversity of Avena genera with wide variability of morphological, agronomical and biochemical characters for oat breeding (loskutov et al., 2011).Investigation of phylogenetic relationships and evaluation of peculiarities of evolutionary processes in Avena species using morphological, botanical, biochemical, chromosomal and molecular markers, 2007-2010. The diploid oat species containing the $\mathrm{Cp}$ genome-Avena pilosa and A. Clauda were studied using Cbanding, fluorescence in situ hybridization with probes pTa71 and pTa794, and electrophoresis of grain storage proteins (avenins). Species with the $\mathrm{C}$ genome differed considerably from the species of the $\mathrm{A}$ genome group in the karyotype structure, heterochromatin type and distribution, relative positions of the 45S and 5S rRNA gene loci, and avenin patterns. These facts confirmed that the $\mathrm{C}$ genome had diverged from the ancestral genome before the radiation of the various A genome. Presumably, further evolution of the A- and C-genome species occurred separately (Shelukhina et al., 2008 Ahmad et al., 2013). The diploid oat species containing the A genome of two types ( $\mathrm{Al}$ and Ac) were studied by electrophoresis of grain storage proteins (avenins), chromosome Cbanding, and in situ hybridization with probes pTa71 and pTa794. The karyotypes of the studied species displayed similar Cbanding patterns but differed in size and morphology of several chromosomes, presumably, resulting from structural rearrangements that took place during the divergence of Agenomes from a common ancestor. In situ hybridization demonstrated an identical location of the $45 \mathrm{~S}$ and $5 \mathrm{~S}$ rRNA gene loci in Avena canariensis and $A$. Longiglumis similar to that in the A. strigosa genome. However, the $5 \mathrm{~S}$ rDNA locus in $A$. longiglumis ( $5 S$ rDNA1) was considerably decreased in the chromosome $3 \mathrm{Al}$ long arm. The analysis demonstrated that these oat species were similar in the avenin component composition, although individual accessions differed in the electrophoretic mobilities of certain components. A considerable similarity of A. canariensis and A. longiglumis to the Avena diploid species carrying the As genome variant was demonstrated (Shelukhina et al., 2008). Tetraploid oat species Avena abyssinica, A. vaviloviana, A. barbata, and $A$. agadiriana were studied using C-banding technique, in situ hybridization with the45S and 5S rDNA probes, and RAPD analysis in comparison with the diploid species carrying different types of the A-genome (A. wiestii, As; A. longiglumis, Al; A. canariensis, Ac; $A$. damascena, Ad, A. prostrata, Ap).The investigation confirmed that all four tetraploids belong to the same AB-genome group; however A. agadiriana occupies distinct position among others. The Cbanding, FISH, and RAPD analyses showed that $A$. abyssinica, A. vaviloviana, and A. barbataare very similar; most probably they originated from a common tetraploid ancestor as a result of minor translocations and alterations of $\mathrm{C}$ banding polymorphism system. AB-genome species are closely related with the Agenome diploids, and an As-genome species may be regarded as the most probable donor of their Agenome. Although their second diploid progenitor has not been identified, it seems unlikely that it belongs to the As-genome group. The exact diploid progenitors of $A$. agadiriana have not been determined; 
however our results suggest that at least one of them could be related to A. Damascene (Badaeva et al., 2010; Ahmad and Zafar., 2014a, 2014b). The chromosome set of Avena macrostachya Balansa ex Coss. Et Durieu was analyzed using C-banding and fluorescence in situ hybridization with $5 \mathrm{~S}$ and 18S- 5.8S-26S rRNA gene probes, and the results were compared with the $\mathrm{C}$-genome diploid Avena L. species. The location of major nucleolar organizer regions and $5 \mathrm{~S}$ rDNA sites on different chromosomes confirmed the affiliation of $A$. macrostachya with the $\mathrm{C}$-genome group. However, the symmetric karyotype, the absence of "diffuse heterochromatin', and the location of large C-band complexes in proximal chromosome regions pointed to an isolated position of $A$. macrostachya from other Avena species. Based on the distribution of rDNA loci on the C-genome chromosomes of diploid and polyploidy Avena species, we propose a model of the chromosome alterations that occurred during the evolution of oat species (Badaeva et al., 2010, Mehraj et al., 2016).

C-banding of chromosomes and in situ hybridization with the probes pTa71 and pTa794 were used for a comparative cytogenetic study of the three tetraploid oat species with the $\mathrm{A}$ and $\mathrm{C}$ genomes: Avena insularis, A. magna, and A. murphyi. These species neither were similar in the structure and C-banding patterns of several chromosomes as well as in the location of the loci 5S rRNA genes and major NOR sites; however, they differed in the number and localization of minor $45 \mathrm{~S}$ rDNA loci as well as in the morphology and distribution of heterochromatin in some chromosomes. According to the data obtained, A. insularis is closer to A. magna, whereas A. murphyiis somewhat separated from these two species. Presumably, all the three studied species originated from the same tetraploid ancestor, and their divergence is connected with various species-specific chromosome rearrangements. The evolution of $A$. murphyi is likely to have occurred independently of the other two species (Shelukhina et al., 2007).

There were around 3.4 million plant genetic resources accessions residing in major gene banks around the world in 1997 which are not being fully utilized, according to FAO. For example, China reports that only $3-5 \%$ of conserved accessions are being utilized in breeding programs. The large investment in germplasm conservation, compared to the benefits from its utilization, has not been significantly resolved by traditional and core collection methodologies, and still remains an issue. The unique identification of plant genetic resources is fundamental to the management of gene banks and plant improvement programs. It is also increasingly important in a world where benefit sharing from the utilization of plant genetic resources is a reality. Such identification information should accompany germplasm as it is physically distributed in the same way as humans carry passports for identification purposes as they travel. This same information can also be used in isolation from a specific accession to identify its presence or absence in any gene bankor collection worldwide. This latter application can be employed to develop global inventories of PGR. Furthermore, it is fundamental to the unique identification of germplasm to know about its origin. In the case of modern cultivars this could be interrupted to include the parentage of an accession. For collected accessions, such as landraces and wild or domesticated relatives, precise information about the collection site is the origin datum. The origin information of accessions, especially for collected germplasm, can be further exploited using modern technologies to enhance the detection of desirable germplasm. For example, GIS and associated database technology provides a platform 
whereby we can recognize the relationship between genotype, environment and evolution in selecting germplasm for plant improvement.

Thus, an innovative combination of traditional and new methodologies can be employed to

1) Identify the wealth of genetic variation contained within global gene banks,

2) To create global inventories and,

3) To increase their use. This will lead to increased knowledge about what is being conserved, the priorities for future collecting, as well as assisting in its management and the sharing of any benefits resulting from its exploitation. The pasture (both alpine and sub-alpine) is mostly inaccessible and the improvement in fodder production therein is a long process. The alternative left is to increase the productivity of fodder on cultivable lands so that fodder shortage is patched up as early as possible. Among various factors, some of the agronomic practices such as determining the optimum sowing dates, cutting management along with nutritional demand for obtaining maximum profitable forage yield per unit area to make the fodder available to livestock especially during lean period of winter were studied (Jehangeer et al., 2013b). Besides it possess high regeneration ability. In the state of Jammu and Kashmir, livestock sector has great potential because of nonvegetarian food habits. In the state, the availability of dry fodder from pastures and cultivable land is $3.26 \mathrm{mt}$ and there is a deficit of $1.05 \mathrm{mt}$ (Jehangeer et al., 2013) for 11 million livestock population. The pasture (both alpine and sub-alpine) is mostly inaccessible and the improvement in fodder production therein is a long process
The exchange of plant genetic resources and their associated information necessitates the unique identification of the germplasm involved. A list of multi-crop passport descriptors (MCPD) has been suggested to provide international standards to facilitate this exchange of germplasm passport information (Alercia et al., 2001). The proposed MCPD were later tested during the establishment of a global inventory of genetic resources for wheat (GIWGR) (Mackay and Skovmand, 2003) and their applicability were discussed and recommendations for improvement suggested. The development of an international standard for passport descriptors to accompany germplasm when exchanged, or to serve as a means of identifying germplasm in shared databases (such as inventories), is an obvious advancement. It was found by Mackay and Skovm and that, ideally, such international standards for descriptors should have certain characteristics:

Individually, or in combination, the descriptors must uniquely identify genotypes,

The number of descriptors should be kept to a minimum,

The descriptors should largely include those readily available from most gene banks, breeding institutes etc.,

Exporting and importing the descriptors into centralized databases should be as transparent as possible. Present strategies for increasing the utilization of conserved genetic resources have not been particularly useful or efficient in improving the use of these resources. They have been particularly poor in their application to large collection like those found a regional gene bank like the Nordic Gene Bank or in the International Agricultural Research Centers like CIMMYT and ICARDA. The most common strategy, the 
core collection strategy, is one designed to catch what you can, rather than catch what you need. Here we propose a new strategy that more fully exploits existing information to maximize utilization of genetic resources. The methodology involved is as follows:

Exploiting existing PGR accession information:

Electronic capture of comprehensive collection site (latitude, longitude, altitude and other locality data).

Capture available characterization and evaluation data.

Capturing novel data:

Collection of anecdotal and production constraint information, through surveys, and subsequent inclusion into the system data model

Locate, obtain, develop and/or derive germplasm identification support information layers:

Incorporate a full range of appropriate environmental (climatic and edaphic) information layers that singularly, or in combination, can assist in the identification of germplasm (e.g. temperature, growing degree days, soil types, agroclimatic zones)

Develop the biological-geographic interface:

Utilize GIS to build two-way information flow between the seed and environment domains.

Conservation management:

Collect necessary information on existing in situ conservation parks

Analyse associated environmental data

Build model for in situ based conservation using climatic and edaphic data layers to perform environmental analysis.

The new technologies suggested here aim to construct a new, objective strategy to identify and utilize germplasm by blending GIS and traditional database technologies. This permits novel, multi-dimensional linkages between biological, genetic resources germplasm and environmental information to be constructed. Such a facility allows us to:

Investigate novel ways to capture and exploit all kinds of knowledge, such as capturing anecdotal information (or "expert opinions") of germ collectors, plant breeders, and other germplasm users, and

To analyse the applicability of current germplasm management strategies, including in situ and ex situ methods, in maximising the global community's conservation and utilization expectations for plant genetic resources. If such strategies were employed for oats, oat genetic resources will become more accessible and be more fully exploited. At the same time it would provide a tracking system for genetic resources use, which appear to be required under the new international treaty just coming into effect this year.

Genetic variation: Wild, cultivated and extra terrestrial Wild Species Hexaploid wild oats are the choice for introgressing genes into the cultivated oat A.sativa, as hybrids are readily formed between the two species and their chromosome pairing is usually almost complete and depending on genotype, regular.

Stable recombinants can usually be recovered quite rapidly. Introgressing of characters from tetraploid and diploid species (with the exception of A.maroccana, A.murphyiand A.insularis) is however a protracted and complex affair but have been accomplished (Ahmad et al., 2014ab).

\section{Cultivated Forms}

Though cultivated forms have a lack of diversity at specific loci, there is still a wealth of variation within this genepool. The study of over 1000 landrace accessions under an EU 
Genetic Resources project (CT99-106) has demonstrated the diversity of genotypes which could be employed to broaden the genetic base of our modern day varieties.

The 'Extra Terrestrial' The mechanisms which release variation not manifest itself in either parent in hybrid combinations, remains largely unclear, but has been attributed to de novo mutation induced by hybridity, complementary gene action or the unmasking of recessive genes (transgresses segregation). Thus although genetic diversity for some traits may be scant, it is nevertheless evident that within the cultivated oat gene pool, there is still locked up and hidden variation (Fu et al., 2003).

\section{Forage oat in India}

Oat (Avena sativa L.) ranks sixth in world cereal production following wheat, maize, rice, barley and sorghum. It is an important winter forage in many parts of the world and is grown as multipurpose crop for grain, pasture, forage or as a rotation crop. Oats are consumed as human food and fodder for cattle. They have a high fat, protein and mineral content. Oat is the most important winter cereal fodder crop grown in winter in North Western, Central India and is now extending to the eastern region. It has excellent growth habit, quick recovery after cutting and good quality herbage. It is a palatable, succulent and nutritious crop. The protein quality of oat is excellent. Oat requires a long and cool season for its growth; therefore, it is successfully grown in the plains and hilly areas of the country. In India it is grown in Punjab, Haryana, Jammu \& Kashmir, Himachal Pradesh, Uttar Pradesh, Madhya Pradesh, Rajasthan, Maharashtra and Bengal.

The total area covered under oats cultivation in the country is about 500000 ha. The crop occupies maximum area in Uttar Pradesh (34\%), followed by Punjab (20\%), Bihar (16\%), Haryana (9\%) and Madhya Pradesh (6\%).Rest of the area is shared by other states viz., Gujarat, Maharashtra, Orissa, Uttaranchal etc. Concerted research efforts at IGFRI, Jhansi, various agricultural universities and centres of All India Coordinated Research Project (Forage Crops) have led to identification of high yielding forage crop sequences for different agroclimatic regions of India. Forage oat is one of the components of several such high yielding remunerative crop sequences which have resulted in increase in forage productivity per unit area and time (Table 1). Oats have assumed considerable importance in India as fodder as well as grain for animal feed particularly calves and young stock, horses, poultry and sheep. On dairy farms oat fodder is a must, as it can be fed green and the surplus converted into silage or hay for use during the scarcity period. The oat crop is a heavy yielder and the average yield varies from 45 to 55 tons of green fodder per hectare.During year 2013-2014 the state had 29,400 ha under oats cultivation and about 80 percent of the cultivated fields in Kashmir used to remain barren during winters because of the severe cold conditions (Anonymous, 2014). This indicates there a lot of scope for quality oat cultivation to improve the economic condition of small and marginal formers after utilizing this barren land during severe cold Ahmad et al., 2013abc; Ahmad et al., 2016d).

Oats can be grown on variety of soils. Almost any reasonably fertile, well-drained soil is suited if temperature and moisture conditions are favourable; although maximum oat yields are usually not achieved until sufficient lime is added to bring the soil $\mathrm{pH}$ up to 5.3-5.7 range. Oat has been shown to tolerate acid soils with a $\mathrm{pH}$ of 4.5 . 
Table.1 Avena species - genome constitution and chromosome number

\begin{tabular}{|l|c|c|}
\hline $\begin{array}{l}\text { Classification } \\
\text { Section Avenotrichon }\end{array}$ & $\begin{array}{c}\text { Chromosome } \\
\text { no. }\end{array}$ \\
\hline constitution
\end{tabular}

The genus Avena is large and diverse and contains both wild and cultivated species of polyploid series with a basic chromosome number of $n=7$. Three naturally occurring 
ploidy levels are known within the genus, diploids $(2 n=2 x=14)$, tetraploids $(2 n=4 x=28)$ and hexaploids $(2 n=6 x=42) \quad($ Table 1) Cultivated oat is believed to have originated from Avena byzantina or A. sterilis.Primary gene pool- Incorporating hexaploid species such as $A$. sativa and $A$. sterilis. Hybrids between wild and cultivated taxa can be produced easily. Introgressing of desired traits is easy through conventional breeding strategies.

\section{Secondary gene pool}

Incorporates tetraploid species such as $A$. maroccana, A. murphyi. Hybridisation is difficult with hexaploids and results in selfsterile F1 (partial female fertility of F1 enables use of backcrossing).Reasonable homology of chromosomes and recombination between tetraploids and hexaploids exists.

\section{Tertiary gene pool}

Incorporates all diploid and some tetraploid species such as $A$. barabata, A. vaviloviana, A.abyssinica, A. agadriana, A. macrostachya. These species are distantly related and hybridisation between diploid and hexaploid is difficult requiring embryo rescue. $F 1$ is self-sterile and cannot be backcrossed conventionally. The sterility of hybrids can be overcome by chromosome doubling, which in turn can be further advanced by selfing/ breakdown of polyploidy and/ or back crossing.

Intergeneric/Wide crosses - Incorporates genera related to Avena, e.g. Arrhenatherum and Helichtotrichon. Crosses with them could provide valuable variation for tolerance to stress conditions and other agronomic traits.

Important Avena species grown for fodder and grain in different places:

A. sativa, A. byzantina - Tropical and temperate countries

A. sterilis-Mediterranean region, SW Asia

A. fatua - SW Asia

A. abyssinica - Ethiopia

A. barbata-Mediterranean region

A. wiestii-UAR, Iran

A. ventricosa-Algeria

India is an agro-climatically diverse country. Broadly it can be divided into 15 different zones. The strategy for development of varieties differs for each zone. At IGFRI, Jhansi and other research centres efforts have been made to develop varieties to suit different zones as well as different systems of fodder production. Inadequate supply of quality feed and fodder is the primary cause of lower productivity of milch animals in India. Management practices to improve the quality and production of forage crops need to be standardized and adopted to meet the forage demand (Jehangeer et al., 2012).

Enrichment of gene pool from exotic sources: Over 500 lines have been procured and maintained at IGFRI. These germplasm lines have been effectively used in the breeding programme. The materials were procured after careful database search. This has helped in building up an impressive germplasm base. The material belonged to primary, secondary and tertiary gene pools. The source countries were USA, Brazil, Mexico, Japan, Canada, Nordic countries, USSR etc.

Cytological studies: Amphiploid derivatives of A. sativa $x$ A. magna were analysed cytologically in different generations and various stable polysomic lines were identified (Pachauri et al., 1993, Kushwah et al., 2004). Stable lines having chromosome constituent of $2 n=42,44,46,50,52,56,66,68,70$ have been identified. These plants also show introgression of morphological traits. However none of the plants showed chromosome numberless than the hexaploid 
maternal parent i.e. $2 n=42$.

A. sativa $x$ A. sterilis- In order to introgress many useful traits like crown rust resistance, high biomass production potential, higher protein content and high growth rate, $A$. sterilis L. EC. $131306(2 \mathrm{n}=6 \mathrm{x}=42)$ a wild progenitor of cultivated oats was hybridised with cultivated oat JHO -851, UPO 212, PA 8253 (A. sativa). The $\mathrm{F} 1$ hybrids were advanced through backcrossing and progenies were evaluated in subsequent generations (Choubey et al., 1996).

Evaluation of interspecific progenies A. sativa $x$ A. sterilis: The F1 hybrids were backcrossed with there current parent $A$. sativa. After the third back crossing, progenies were selfed and desirable plants were selected in subsequent generations. Finally, back cross derived progenies were tested for their performance with respect to forage yield and related traits. The genes of practical value existing in the wild oat $A$. sterilis might be useful in improving the cultivated oats for forage yield and related traits. It will be better to study more A. sterilis lines in relation to their combining ability with A. Sativa lines for different traits. It is evident that A. sterilis may become one of the most important sources of creating genetic variability for improving the cultivated forage oats.

Genetic stocks developed Polysomic lines:

An array of cytogenetic stocks developed with chromosome number $2 \mathrm{n}=42,44,46,50$, 52, 56, 58, 60, 62, 64, 66, 70 from A. sativa $\mathrm{x}$ A. maroccana cross followed by amphidecaploidy.

Induced tetraploid lines of A. strigosa. Identification of a spontaneous mutant in oat with three style pistil (as a marker). The trait shows complete penetrance but $12-60 \%$ expressivity.
Dual (forage cum grain) purpose oats with compact panicle like wheat - An array of advanced generation selections developed by crossing A. sativa (compact types) with $A$. sativa (loose types). The lines combine stiff straw, good grain yield and better forage quality.

Multi-locational testing of oat breeding lines under All India Co-ordinated Project - India, has a well-managed system for evaluation of breeding lines for release and notification for cultivation by farmers. Entries after station trials are entered in All India co-ordinated trials.

These trials consist of three steps: - Initial evaluation trial, Advanced varietal trial -1 and Advanced varietal trial -2 . The entries are promoted to each subsequent step after a rigorous evaluation based on green fodder yield, dry matter yield, crude protein content, disease incidence etc. The entries which are promoted to advanced varietal trial -2 are also evaluated separately for seed yield, agronomic practices, disease incidences under hot spot and artificial inoculation condition as well as detailed quality parameters such as Crude protein, ADF, NDF, IVDMD etc. Entries, which are better than the control by a sufficient margin, are put before a committee for identification. A committee at national level further considers these recommendations. These steps are essential for the release and notification of a variety for use by farmers.

\section{The preservation of oats in gene banks}

Most oat species can be easily stored as seeds in gene banks. The European oat collection, available through web based information systems, contains approximately 35.000 entries (accessions), stored and made available as seed samples. They comprise four cultivated and about 20 wild species in the 
genus Avena. Figure 3 shows the impact of domestication on the appearance of seeds. Seeds of the wild species (upper row) have hairs and awns, which facilitate their distribution by wind and animals. But they are not suitable for mechanical operations, like sowing and harvesting, or for animal feeding. Cultivated forms in the mid-dle and lower row have mostly lost hairs and awns, although most cultivated oats are still a husked cereal. Nevertheless, free threshing forms (so called naked oats) have already been bred of the sand oat (diploid) as well as of the common (hexaploid) cultivated types (right hand side of the middle and lower row).

Besides creation of genetic stock collections, the main task of the Department is the complex study of the collected germplasm and identification of sources and donors of the economically important traits for breeding purposes. The prolonged study of the oat collection, a large number of early local and breeding forms originating from different regions of oat cultivation have been identified among $A$. sativa and $A$. byzantina accessions. Considerable variation of duration of different periods in plant development is characteristic at the level of a species of some wild forms. The most important factors influencing duration of the vegetative period of a plant, and especially the first half of the period, are the daylight duration and the temperature regime. The results of long-term studies performed together with the Department of Plant Physiology of VIR have demonstrated differences in response to photoperiod and vernalization.

The problem of dwarfness is closely linked to the problem of lodging resistance in oat, the latter occupying a special place among the breeding objectives for this crop. This problem attracts a special attention because of the plant habitus features and high wind age of the panicle. The investigations of recent years have identified some perspective forms which may be used as sources combining dwarfness with high grain yield per panicle and good grain quality. Hybridization and multistage selections have yielded some stable, productive forms which transfer the semi-dwarf stem trait in further crosses. The work has resulted in creation of 15 oat donors which are the donors of semi-dwarfness and lodging resistance.

A complex psychopathological evaluation of the entire specific diversity of the Avena genus facilitates selection and utilization of new sources and donors of resistance thus broadening genetic basis of the new created oat cultivars. Sources of resistance to the main oat pathogens and pests, among which are crown and stem rusts, various leaf blights, smuts and Fusarium fungi have been found for different regions of the country. Numerous accessions of cultivated species and especially forms of wild oats have been identified as possessing a high degree of resistance (Loskutov, 2010).

From the point of view of nutritional and fodder qualities, biochemical characteristics of oat grain are of the highest importance. These are the protein content and amino acid composition, oil content and fatty acid composition. Recently, the list of biochemical component determining high nutritional value of oats has been extended by including $\beta$ glucans, tokopherols, sterols, avenanthramides and other components. At pre-sent, this trend in studies of the collection is the most promising one that has resulted in the identification of interesting initial material (Loskutov, 2007; Loskutov and Rines, 2017).

Future thrust to breed as a specialty crop based on its end use.

To breed for specific cropping system/ specific situations. 
To breed varieties which can be grown without use of expensive herbicides i.e. weed tolerant varieties.

To breed varieties with horizontal resistance to diseases.

Varieties with value-added traits - viz., with higher fibre content - dietary value for human consumption.

Varieties with reduced hull percentage naked oats.

Variety exclusively for forages.

\section{References}

Ahmad M., and Zaffar, G. (2014a). Betaglucan and Grain protein studies of oats (Avena sativa L.) under temperate conditions. Electronic Journal of Plant Breeding. 6(1): 355-359.

Ahmad M., and Zaffar, G. (2014b). Study of heterosis, inter-relationship and path analysis of green fodder yield and its contributing traits in oats (Avena Sativa L.). Research Journal of Agriculture Sciences. 5(2): 235-241.

Ahmad. M., Zaffar, G., Zeerak, N.A., Dar, Z.A,. Mir, S.D., and Rather, M.A. (2010a). Explotitation of genetic variability in oats germplasm for harnessing higher fodder productivity. Range management and Agro forestry issue B; pp153-154.

Ahmad. M., Zaffar, G., Mir, S.D., Dar, Z.A., Razvi, S.M., Iqbal, S., andHabib, M. (2014c).Geneticanalysis for fodder yield and its important traits in oats (Avena sativa L.).Indian Journal of Genetics and Plant Breeding. 74(1):112-114

Ahmad. M., and Zaffar, G.(2014c). Heterosis Expression, Correlation and Path Analysis Studies of Grain Yield and its Contributing Traits in Oats (Avena Sativa L.) Research Journal of Agriculture Sciences. 5(2):264-268.

Ahmad. M., Zaffar, G., Razvi S.M., Dar Z.A. (2015a). Genetic analysis for beta glucan, grain protein and other important traits in oats (Avena sativa L.).Indian Journal of Genetics and Plant Breeding. 75(1):136-139.

Ahmad., M, Zaffar G., Razvi S.M., Dar Z.A., Khan M.H. and Ganie S.A. (2013b). Combining ability study in oat (Avena sativa L.) for physiological, quality traits, forage and grain yield. African Journal of Agriculture Research, 8(43): 5245-5250.

Ahmad., M., Gul-Zaffar, B.A. Wani, Uzma Mehraj, Z.A. Dar, Ajaz A Lone, M.A. Rather (2016a). Genotype $x$ environmental interaction and stability analysis for grain quality and yield in oats (Avena sativa L.).Electronic Journal of Plant breeding.7(4): 11321135.

Ahmad., M., Zaffar G., Mehraj U., Jehangir IA., Lone AA. (2015b). Stability analysis for forge quality traits in Oats (Avena Sativa L.) over environments. International Journal of Science and Nature. 6(4); 590-595.

Ahmad., M., Zaffar G., Mir SD., Dar ZA., Dar SH., Iqbal S., Bukkhari SA., Khan GH., Gazal A (2013c) Estimation of correlation coefficient in oats (Avena sativa L.) for forage yield, grain yield and their contributing traits. International Journal of Plant Breeding and Genetics.pp1-4

Ahmad., M., Zaffar G., Razvi SM., Mir SD and Rather MA. (2013d). Stability properties of certain oats genotypes for major grain yielding characteristics. International Journal of Plant Breeding and Genetics. Pp, 1- 6

Alercia, A., Diulgheroff, S. and Metz, T. 2001. Multi-Crop Passport Descriptors. FAO (Food and Agricultural Organization of the United Nations), IPGRI (International Plant Genetic Resources Institute). 
Annamaa, K., Kukk, V. (2012).collection and conservation of plant genetic resources for food and agriculture in estonia. Current Science. 643-645

Anonymous, 2014b. Economic survey, directorate of economic and statistics, Govt of Jammu and Kashmir. pp 11

Badaeva E. D., Shelukhina O. Yu., Goryunova S. V., Loskutov I. G., Pukhalskiy V. A. Phylogenetic Relationships of Tetraploid ABGenome Avena Species Evaluated by Means of Cytogenetic (C-Banding and FISH) and RAPD Analyses. Journal of Botany. Volume 2010, Article ID 742307, 13 pages doi:10.1155/2010/742307

Choubey, R. N., S. N. Zadoo and A. K. Roy. 1996. Analysis of forage yield and related traits in back-cross derived progenies of interspecific matings (Avena sativa $\mathrm{x}$ A. sterilis) of oats. Crop Improv. 23(1):155- 157.

Fu., Christoph U. Germeier, Lothar Frese and Brigitte Laliberte. (2003). Towards a global strategy for the ex situ conservation of oat genetic resources Crop Science 43:1989-1995.

Jehangir, I. A Khan, H.U. Faisul-ul-

Rasool and Mahdi, S.S. (2012).Yield

And Quality Of Fodder Oat (Avena sativa L.) As Influenced By Sowing Dates, Fertility Levels And Cutting Management. Applied Biological Research 14 (2): 164-167,

Jehangir, I. A., Khan, H.U. Faisul-ulRasool and Mahdi, S.S. (2013a). Productivity Of Fodder Oat (Avena sativa) Under Different Sowing Times, Fertility Levels And Cutting Management In Temperate Environment. Indian Journal of Agronomy 58 (4): 119_122

Jehangir, I. A Khan, H. U. Faisul-ulRasool and Mahdi, S.S.(2013b). Yield and economics of oats (Avena sativa $\mathrm{L}$.) as influenced by fertilizer and cutting management at different sowing dates. Range Mgmt. \& Agroforestry 34 (2) : 179-181

Kushwah, N., S. N. Zadoo and R. N. Choubey 2004.Breakdown of polyploidy and isolation of stable polysomics in amphidecaploid (Avena sativa $L x$ A. maroccana $G d g r$.). Cytologia 69(1):

Loskutov I.G. 2000. Proc.6-th Inter. Oat Conference, 248-253;

Loskutov I.G. 2001.Euphytica 117: 125-131; Loskutov I.G. 2002. Oat Newsletter, v.48;

Loskutov I.G. 2003. Report of ECP/GR Cereals Network, 1-st meeting, Armenia, IBPGR;

Loskutov I.G., 2001. Oat Newsletter, v.47.

Loskutov I.G., Rines H.W. AVENA L. Wild Crop Relatives: Genomic \& Breeding Resources. Cereals. Editor: Chittaranjan Kole. Springer - Heidelberg, Berlin, New York, Tokyo. 2011. 109-184 p.Avena webpage http://vir.nw.ru/avena/

Loskutov, I. G. and Rines, H. 2017. Avena L. In Kole, C. (ed.): Wild Crop Relatives: Genomic \& Breeding Resources. Springer, Heidelberg, Berlin, New York.160 pp.

Loskutov, I. G. 2007. Oat (Avena L.).Distribution, taxonomy, evolution and breeding value. VIR.S-Pb. 336 pp. (in Russian).

Loskutov, IG (2010). Genetic resources and main directions and results of barley and oat breeding in Russia .Agronomy Research, 8(3): 673-680.

Mackay, M. C. and B. Skovmand. 2003. Identification of Data for the Exchange and Tracking Of Plant Genetic Resources. In Proceedings of Tenth International Wheat Genetics Symposium, 1-6 September, Paestum, Italy.

Murariu, D., Placinta, DD., christop, U. 
(2013). Quality Characteristics of European Avena Genetic Resources Collections, Romanian Agricultural Research, 3: 45-50.

PachauriAmita and R. N. Choubey. 1994. Transgressive segregation for quantitative traits in interspecific matings (Avena sativa $x$ A. maroccana) of oats. Geobios, 21(1): 39-43.

Shelukhina O. Yu., Badaeva E. D., Brezhneva T. A., Loskutov I. G., Pukhalsky V. A. Comparative Analysis of Diploid Species of Avena L. Using Cytogenetic and Biochemical Markers: Avena pilosaM. B. and A. claudaDur. Russian Journal of Genetics, 2008, Vol. 44, No. 9,p. 1087-1091.

Shelukhina O. Yu., Badaeva E. D., Loskutov I. G., Pukhal'sky V. A. A Comparative Cytogenetic Study of the Tetraploid Oat Species with the $\mathrm{A}$ and $\mathrm{C}$ Genomes: Avena insularis, A. magna, and A. murphyi.Russian Journal of Genetics, 2007, Vol. 43, No. 6, pp. 613-626.

Uzma Mehraj, Mushtaq Ahmad*, Ishfaq Abidi, Gul-Zaffar and Asif B. Shikar I. (2016). Participatory varietal selection in fodder oats under temperate conditions of Kashmir valley.Indian Journal of Genetics and Plant Breeding. 76(2): 217-220.

\section{How to cite this article:}

Mushtaq Ahmad, I. A. Jehangir, R. Rizvan, Showkat Ahmad Dar, Shahida Iqbal, S.H. Wani, U. Mehraj and Rohie Hassan. 2020. Phylogenetic Relationship of Oats (Avena sativa L): A Guide to Conservation and Utilisation of Genetic Resources. Int.J.Curr.Microbiol.App.Sci. 9(11): 831-845. doi: https://doi.org/10.20546/ijcmas.2020.911.101 